\title{
Presentation-rate effects and age differences in children's free recall
}

\author{
JAMES W. HALL and MARGARET B. TINZMANN \\ Northwestern University, Evanston, Illinois
}

\begin{abstract}
In two experiments, free recall of lists of familiar unrelated words was higher for sixth-graders than third-graders and for lists presented four times at a 1-sec rate than once at a 4-sec rate before testing. In neither experiment did the interaction between age and presentation rate approach significance. Thus, the age difference in recall apparently was due not to differences in rehearsal strategies, but principally to semantic memory differences that influence the memorial effectiveness of initial perceptual operations as well as rehearsal.
\end{abstract}

In a typical free-recall (FR) task, the study interval following each item may be viewed as a period during which memory input is continuous, driven first by relatively automatic perceptual operations and then by study (rehearsal) activities that are deliberately initiated and guided by the subject (Craik \& Lockhart, 1972). It has been this second source of memory input, subject-controlled study activities, that has received the bulk of empirical and theoretical attention over the past decade or so. This has been particularly true in developmental psychology, in which quite strong positions have been taken regarding the importance of rehearsal strategies in accounting for developmental differences in recall. Probably the most extreme position in this respect has been taken by Brown (1975), who argued that substantial developmental differences are found only for tasks susceptible to strategy use and are due to that use (also see Brown, Bransford, Ferrara, \& Campione, 1983, and Campione, Brown, \& Bryant, 1985).

There seems to be ample evidence that increases in the use of effective rehearsal strategies do occur and are related to increases in recall performance. Of these strategies, the one that appears to be most critical for FR of unrelated words under ordinary conditions is a kind of review strategy in which each study interval is used to rehearse some earlier list items in addition to the item just presented (see Ornstein \& Naus, 1978). However, there also is reason to expect substantial developmental differences to be found under circumstances in which such rehearsal strategies are not involved. That is, Brown's (1975) position seems to give short shrift to the developmental implications of changes in the nature of semantic networks activated by perceptual processing. There is little doubt that such activation occurs prior to the initiation of subject-controlled rehearsal and that it results in substantial memory input. And there is no doubt that there

We are grateful to the district officials, teachers, and children in the Mt. Prospect schools, whose cooperation made this study possible. Requests for reprints should be mailed to James W. Hall. Department of Psychology, Northwestern University. Evanston. IL 60201. are substantial developmental increases in the richness of semantic networks (e.g., Chi, 1978). It also is clear that recall depends heavily on the amount or degree of semantic processing (e.g., Craik \& Tulving, 1975), which, other things being equal, may be expected to vary with the richness of the semantic networks that are activated.

On the basis of the above reasoning, one would expect substantial developmental differences in FR corresponding to the developmental differences in semantic memory whether semantic activation derives from strategic rehearsal or from initial perceptual processing. There are, in fact, data that confirm that expectation. Wilkinson and Koestler (1983) found a substantial superiority of 19-yearolds over 11-year-olds in FR of unrelated words presented at the rate of $1 \mathrm{sec}$ per item, a rate that was selected particularly to eliminate strategic rehearsal. Although Wilkinson and Koestler provided no direct evidence that strategic rehearsal did not occur, there is independent evidence from Stoff and Eagle (1971) that a 1-sec presentation rate is not sufficient for adults to fully implement effective rehearsal activities. At the very least, such a rate would seem to offer a very minimal opportunity for such activities.

A critical question not addressed by Wilkinson and Koestler's (1983) experiment is whether the age differences in FR would have been even larger if the presentation rate had been slower and, therefore, more conducive to the execution of rehearsal strategies. If age differences in recall are due chiefly to such strategy differences, precisely such an interaction would be expected. The two experiments reported here examined that possibility by administering a FR task, using lists of unrelated familiar nouns, to children in Grades 3 and 6 and under one of two presentation conditions. In one condition, lists were presented once at the rate of $4 \mathrm{sec}$ per item. In the second condition, a 1-sec rate was used, and to equate total study time (TST), the lists were presented four consecutive times before testing. This step of holding TST constant while varying presentation rate (and frequency) was taken to avoid scaling problems that otherwise might complicate interpretation of an age $\times$ presentation rate inter- 
action or the absence thereof. The scaling problem would arise because FR would be far higher after a single presentation at a 4-sec rate than after a single presentation at a 1-sec rate. Unequivocal evaluation of a possible interaction under such conditions is not possible (see Baron \& Treiman, 1980, and Loftus, 1978).

The only substantial difference between the two experiments was that assignment to rate conditions was reversed from Experiment 1 to Experiment 2. Thus, the two experiments are reported together here.

\section{METHOD}

\section{Subjects and Design}

Experiment 1. The subjects were 32 Grade 3 [mean chronological age $(\mathrm{CA})=8.3$ years] and 32 Grade 6 (mean $\mathrm{CA}=11.9$ years) children in a public elementary school near Chicago. In each grade, 16 children were assigned to the $1 \times 4$ condition, in which each of four lists was presented once at a 4 -sec rate, and 16 were assigned to the $4 \times$ 1 condition, in which each list was presented four times at a 1-sec rate before testing.

Experiment 2. Experiment 2 was conducted 5 months after Experiment 1 , and used the same subjects. The design of Experiment 2 was the same as that of Experiment 1, except that the assignment of rate condition to subjects was reversed. Thus, the subjects who served in the $1 \times 4$ condition in Experiment 1 served in the $4 \times 1$ condition in Experiment 2.

\section{Materials and Procedure}

Experiment 1. From a pool of 48 highly familiar, one-syllable nouns, four lists of 12 words each were formed by random assignment. The lists were read into a tape recorder either four consecutive times in the same order at a 1-sec rate or one time at a 4-sec rate. Each word was pronounced once, as clearly and as quickly as possible. The idea was to minimize the time between the onset of articulation and the onset of effective perceptual processing.

The experimental session began with an explanation of the task, followed by playing of the first list, and then by a 1-msec test period in which the child gave recall orally. The first list was regarded as practice and was not scored. The remaining three lists then were presented, each followed by a test period, in just the same way as for the practice list.

Experiment 2. A new pool of 48 words similar to those in Experiment 1 was constructed for Experiment 2. In all other respects, the materials and procedures were identical for the two experiments.

\section{RESULTS AND DISCUSSION}

In each experiment, a presentation rate $\times$ grade level ANOVA was applied to the sum of recall scores for the three nonpractice lists; the means of the scores are shown in Table 1 . In each experiment, recall was significantly $(\mathrm{p}<.05)$ higher at Grade 6 than at Grade 3 and for the 1 -sec than for the 4-sec presentation rate $[\operatorname{Fs}(1,56)=$ 14.18 and 5.41 for grade level and 10.00 and 5.95 for presentation rate, MSes $=11.02$ and 18.97 for Experiments 1 and 2 , respectively]. In neither experiment did the presentation rate $\times$ grade level interaction approach significance.

The overall superiority of the faster presentation rate is consistent with adult studies that have compared the same presentation rates (Hall, Smith, Wegener, \& Underwood, 1981, Experiment 2; Roberts, 1972). In the Hall et al. experiment, TST was equated by covarying the number of list presentations prior to testing, as in the
Table 1

Mean Recall Percentages

\begin{tabular}{cccccc}
\hline \multirow{2}{*}{$\begin{array}{c}\text { Grade } \\
\text { Level }\end{array}$} & \multicolumn{2}{c}{ Experiment 1} & & \multicolumn{2}{c}{ Experiment 2} \\
\cline { 2 - 3 } \cline { 5 - 6 } & $4 \times 1$ & $1 \times 4$ & & $4 \times 1$ & $1 \times 4$ \\
\hline 6 & 49 & 42 & & 44 & 37 \\
3 & 41 & 33 & & 38 & 29 \\
\hline
\end{tabular}

present experiments. In Roberts's experiment, TST was equated by covarying list length. The similarity of the results using these different procedures to equate TST suggests that indeed the 4-sec rate is slower than is optimal for adult FR. That finding in the present experiment suggests the same conclusion in the case of children of the ages studied here. Apparently, for both adults and children, the study activities in which subjects typically engage following identification of an item begin to decline in memorial effectiveness well within $4 \mathrm{sec}$ following presentation. At that point, they are considerably less effective (per unit of processing time) for FR than is the perceptual processing that occurs immediately following presentation, presumably with little if any conscious guidance.

It is particularly interesting that the degree of superiority of the older children did not differ statistically as a function of presentation rate. This was not entirely unexpected, in view of Wilkinson and Koestler's (1983) earlier finding of a substantial superiority of 19-year-olds over 11-year-olds at rapid presentation rates that appeared to eliminate strategic rehearsal. Although the present absence of a significant interaction raises the usual issues regarding acceptance of the null hypothesis, the weight of the evidence suggests that presentation-rate effects on FR of unrelated words are similar across this particular age range. This conclusion is buttressed by an experiment just completed by the second author (Tinzmann, 1984), wherein there again was no hint of an interaction between presentation rate and age. In that experiment, presentation was visual at rates of $1.2,2.4$, and $4.8 \mathrm{sec}$ per item, and the subjects were children in Grades 4 and 8 .

What is implied with respect to memory development by the above result? First, the substantial age difference in FR at the 1-sec presentation rate seems most likely to be chiefly the result of differences in the nature of the semantic networks that are activated in a relatively automatic fashion by perceptual operations. Such an interpretation is consistent with current theoretical positions that acknowledge input from such activation (e.g., Bradshaw \& Anderson, 1982), with the apparent time requirements of effective subject-controlled activities (Stoff \& Eagle, 1971), and with evidence on semantic memory (knowledge) development (Chi, 1978).

It is generally acknowledged that the effectiveness for FR of subject-controlled study activities also depends on semantic processing (e.g., Lockhart, Craik, \& Jacoby, 1976). One would expect, then, that even if the rehearsal activities of the older and younger children were identical, the memorial consequences of those activities would differ because of differences in semantic networks acti- 
vated by those deliberate study behaviors. Thus, the pattern of results obtained here seems to be just what would be expected on the basis of developmental changes in semantic memory characteristics without any additional assumptions regarding strategic rehearsal differences. Of course, the latter differences also may have existed and even may have played some part in producing the recall differences at the slower presentation rate. However, that part seems to have been a minor one in view of the absence of a significant presentation rate $\times$ age interaction.

It is important to note that the above conclusion may be quite restricted in its generality. It seems likely that the relative importance of semantic memory and strategic rehearsal differences varies with the age range involved as well as with task characteristics. With respect to the latter, it is perhaps pertinent that little of the evidence cited by Brown et al. (1983) and Campione et al. (1985) regarding the importance of strategy development comes from studies involving FR, especially FR of unrelated words; probably the most impressive evidence pertains to memory for order information. Thus, the presentation rate $X$ age interaction that was not present here might obtain with tasks such as serial recall or FR of categorized lists, or even with the present tasks if an older group of subjects were included. We believe that presentationrate manipulations offer a promising approach to the investigation of these questions regarding the source of developmental differences in memory.

\section{REFERENCES}

Baron, J., \& Treiman, R. (1980). Some problems in the study of differences in cognitive processes. Memory \& Cognition, 8, 313-321.

BRADShaW, G. L., \& ANDERSON, J. R. (1982). Elaborative encoding as an explanation of levels of processing. Journal of Verbal Learning and Verbal Behavior, 21, 165-174.
Brown, A. L. (1975). The development of memory: Knowing, knowing about knowing, and knowing how to know. In H. W. Reese (Ed.), Advances in child development and behavior (Vol. 10). New York: Academic Press.

Brown, A. L., Bransford, J. D., Ferrara, R. A., \& Campione, J. C. (1983). Learning, remembering, and understanding. In P. H. Mussen (Ed.), Handbook of child psychology (Vol. 3): Cognitive development. New York: Wiley.

Campione, J. C., Brown, A. L., \& Bryant, N. R. (1985). Individual differences in learning and memory. In J. R. Sternberg (Ed.), Human abilities: An information-processing approach. New York: Freeman.

CHI, M. T. H. (1978). Knowledge structures and memory development. In R. S. Siegler (Ed.), Children's thinking: What develops? Hillsdale, NJ: Erlbaum.

CraIK, F. I. M., \& LockHART, R. S. (1972). Levels of processing: A framework for memory research. Journal of Verbal Learning and Verbal Behavior, 11, 671-684.

Craik, F. I. M., \& Tulving, E. (1975). Depth of processing and retention of words in episodic memory. Journal of Experimental Psychology: General, 104, 268-294.

Hall, J. W., Smith, T. A., Wegener, S. L., \& Underwood, B. J. (1981). Rate and frequency as determinants of learning with complete and discrete list presentation. Memory \& Cognition, 9, 360-367.

Lockhart, R. S., Craik, F. I. M., \& JaCoby, L. (1976). Depth of processing, recognition, and recall. In J. Brown (Ed.), Recall and recognition. London, Wiley.

LofTUS, G. R. (1978). On interpretation of interactions. Memory \& Cognition, 6, 312-319.

OrnSteIn, P. A., \& NAUS, M. J. (1978). Rehearsal processes in children's memory. In P. A. Ornstein (Ed.), Memory development in children. Hillsdale, NJ: Erlbaum.

ROBERTS, W. A. (1972). Free recall of word lists ranging in length and rate of presentation. Journal of Experimental Psychology, 92, 365-372.

STOFF, D. M., \& EAGLE, M. N. (1971). The relationship among reported strategies, presentation rate, and verbal ability and their effects on free-recall learning. Journal of Experimental Psychology, 87, 423-428.

TinzmanN, M. B. (1984). [Presentation-rate effects on children's free recall]. Unpublished raw data.

Wilkinson, A. C., \& Koestler, R. (1983). Repeated recall: A new model and tests of its generality from childhood to old age. Journal of Experimental Psychology: General, 112, 423-451.

(Manuscript received for publication February 7, 1985.) 